\title{
Prospects for Further Rock Cutting Mechanisms Development
}

\author{
M.B Novoseltseva ${ }^{a}$, E.N Pashkov ${ }^{b}$ \\ Tomsk Polytechnic University, 30 Lenin Ave., Tomsk, Russia \\ anovmv@tpu.ru, bepashkov@tpu.ru
}

Keywords: hydraulic power pulse systems, pulse, high pressure sleeve, hydropower rock-drilling machines, peenless hydropulse mechanism.

\begin{abstract}
In this research power rock cutting mechanisms are considered. Impact and vibratory impact mechanisms are presented, their design characteristics are given. The new peenless power pulse hydraulic mechanism is considered, its operating principle is described, and the schematic diagram is provided. The new system can be used at building of the new rock-drilling machines with a hydraulic actuator for the intensification of the process of rocks destruction.
\end{abstract}

\section{Introduction}

Now in the mining industry and in many other areas of industry power pulse machines have an important function. The power pulse system is a device or the mechanism in which the impulses of force of a certain frequency and intensity influencing some processed environment are generated. In power pulse systems the drive type defines nature of working processes: hydro-, pneumo - the electric drive. One of the directions of improvement of such machines is increasing both impact energy, and frequency.

The existing power pulse machines can be divided into two types, such as impact and vibratory impact.

\section{Impact power mechanisms}

The impact as the mechanical phenomenon is characterized by two main properties. First, speed of a fulfillment: during time, very small from the point of view of mechanics (an order of fraction of milliseconds) the speed of points of mechanical system sharply changes. Secondly, considerably bigger emergence (also fast disappearance) of impacts, that during impact all forces, except these, it is possible not to consider.

For greater efficiency of the machines operation of impact actions they are organized so that impacts follow systematically, for example at regular intervals, for real technical systems they change in the range of $10^{-3}-10^{-5} \mathrm{sec}$. [2].

Owing to the chosen drive of the impact machine also characteristics of machine details follow.

Let's consider power pulse systems with a hydraulic actuator. There is a wide range of the application of hydro impact mechanisms: in working bodies of forging and the pile-driving hammers, in devices for separation and crushing of coal, ores, rocks, in drilling rigs, the chipping hammers and rock drilling hammers, etc.

Hydraulic power pulse systems differ in quantity and a type of knots and details, as well as the way of their configuration. In various branches of machinery the different systems of the classification of similar machines are accepted.

In this work [1] the following classification of hydraulic shock mechanisms is offered:

- by quantity of moving elements:

$\circ$ single-peen
$\circ$ dynamically balanced
$\circ$ multiple-pean

- by type of camera operation:

○ with hydraulic working chambers

○ with pneumatic chambers 
○ with the operated chamber of reverse motion

- by operation of working chambers:

o with two monitoring chambers

○ with the operated chamber of the working course

o with the operated chamber of reverse motion

- by means of removal of the fulfilled liquid:

0 in oil box

$\circ$ in the auxiliary chamber

o combined

The most general classification applied to machines of all types is division of power pulse systems into machines of unary and double action, analog of this classification in relation to a hydraulic actuator of unilateral and bilateral action.

In machines of unary action energy of a stream of liquid is used for performance of the running of mobile impact weight (the most successful name of this element the piston - peen, or it is simple peen) single acting. If under the influence of liquid energy there is a peen working stroke, i.e. such which comes to an end with impact to an anvil, the power pulse system is the machine of direct action. When using energy of liquid for peen return (idling) hydraulic power pulse system is called as the machine of the return action.

Implementation of the working and idle strokes at an elevated pressure of liquid characterizes power pulse systems of double action.

As force moving the peen in the direction opposite to the movement at an elevated pressure the force of a spring is usually used, which is resistance force at the movement under the influence of energy of liquid. Along with it force of a spring can be used also as an auxiliary driving force along with hydraulic force [2].

The schematic diagrams of power pulse systems of unary action with the springs operating for compression at the movement of the peen under the influence of energy of liquid are given in Fig. 1. The valve unit in these schemes forms the surfaces of two mobile elements (the peen and the valve), each of which can serve both a seat, and the valve.

Working liquid from the bringing pipeline (pressure line) comes to a piston chamber $I$ in which the working surface of the piston-peen is located. The valve couple forms variable local hydraulic resistance, having overcome which the liquid stream in a rod part of the peen passes through the channel in the exhaust (drain) chamber $I$, interconnecting with the drain highway.

The stream of liquid is blocked at a joining of the peen 1 with valve 4 . Chambers $I$ and $I I$ are separated, and in this case pressure increases in chamber $I$. The peen together with the valve moves, overcoming force of resistance of springs 2 and 3 , for the scheme of direct action (Fig. 1, a) down, in the machine of the return action (Fig. 1, b) - up.
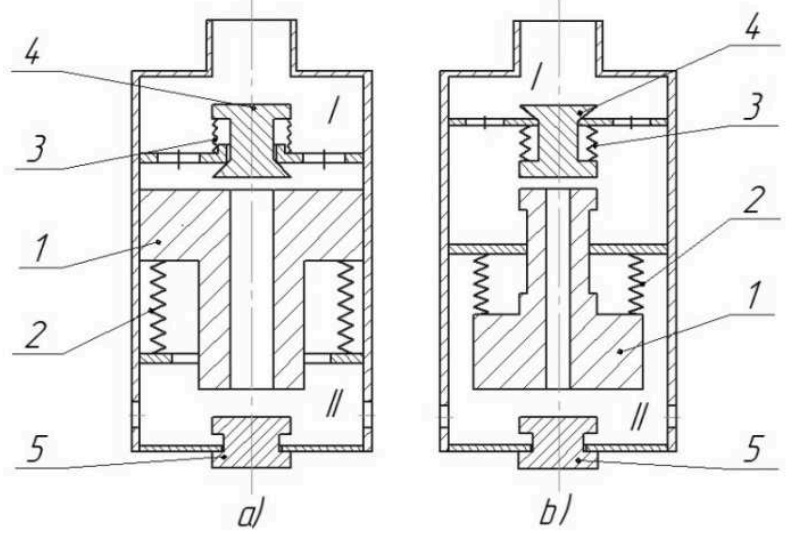

Fig. 1. Schematic diagrams of systems of unary action: direct (a) and return (b). Where 1 piston-peen, 2 - spring of peen; 3 - valve spring; 4 - valve; 5 - anvil 


\section{Vibratory impact power mechanisms}

The modern industry and construction have manual vibratory impact machines of the different designs. In mechanical engineering, for example, screwdrivers and nut setters are applied by means of which the threaded connections are gathered and demolished; various vibratory impactt hammers for a clinching, stampings, stumps of castings, upholsteries of scale and many other operations are widely used.

In construction manual vibratory impact machines destroy natural soil, asphalt, concrete, punch passes and niches, drill openings, spike, and etc. In mining industry jackhammers and punchers are necessary for wells and shots drilling. In many fields of industry manual tampers are used, with their help the soil or forming mixes in the foundries are compacted. At service of the railroads the manual ram impact machines for tracks surfacing are applied. This list can be continued, however, it is clearly from the above how great the range of application of the manual impact machines is. They are irreplaceable, when owing to any circumstances, it is impossible to use stationary devices. Resonant fluctuations in vibratory impact systems essentially differ from fluctuations in systems without impacts. If in the last the maximum amplitudes are observed near the only resonant frequency withdrawal from which though caused recession of amplitude, but nevertheless qualitatively it didn't affect the properties of the mode, in vibratory impact systems the most intensive modes exist near failure frequency. Here the small withdrawal coming, for example, owing to casual change of parameters, can bring to high-quality change of a picture of the movement: the vibratory impact modes can suddenly stop. At the same time the operation at these frequencies is especially tempting: it is natural desire "to squeeze out" the greatest intensity from the machine.

All said above is of great importance for the theory and practice of the machines of vibratory impact action. Need of operation near the frequency of failure defines very interesting problem. It is necessary to learn to stabilize the most unstable modes.

The vibratory impact immersing machines in the modern industry or in construction are wide range: the springless and spring vibrohammers, vibrohammers creating either longitudinal, or longitudinally rotary impacts, vibrohammers with use of additional static forces, etc. The vibratory impact way of immersion is very effective, but now the mass of the immersed bodies, as a rule, doesn't exceed of $5 \mathrm{t}$. It is known that on impact of two bodies energy from one to another is transferred in the best way in a case of approximate coincidence of their masses. Therefore for effective process the mass of the immersed pile has to be equal approximately to the mass of the drummer of a vibrohammer. Calculations and practice show, however, that it is still impossible to create a durable and reliable vibrohammer with the drummer weighing more than $5 \mathrm{t}$. For immersion of more massive bodies a vibration way is applied [3].

Vibrohammer is the shock and vibration machine for immersion (blockage) in the soil, as well as extraction from it ferroconcrete, wooden and metal piles, tongues, pipes, and other elements. Unlike a vibratory driver, the vibration exciter is connected to a cap of the immersed element by a spring suspension bracket (Fig. 2) and together with vibration impact on the immersed element transfers to it periodically impact impulses intensifying immersion process. Ipmacts are struck by the heads of the vibration exciter to an anvil cap of the immersed element. There can be vibrohammers with one or two electric motors (the last are most widespread). 


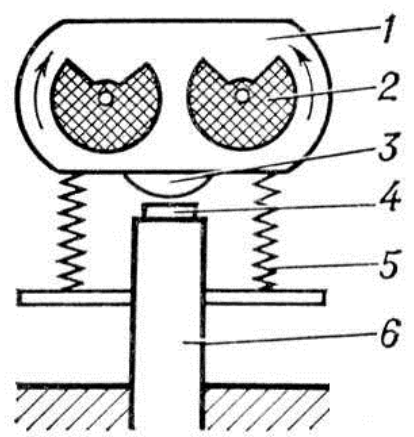

Fig. 2. Schematic diagram of vibrohammer: 1 -vibration exciter of directed fluctuations; 2 — balance weight; 3 — peen; 4 -anvil; 5 -spring suspension bracket; 6 -pile.

\section{Peenless power hydropulse mechanism}

At the present time the power pulse machine of a new type, called as peenless power hydropulse mechanism is being researched in the Department of theoretical and applied mechanics of National Research Tomsk Polytechnic University.

The schematic diagram of the mechanism is submitted in Fig. 3.

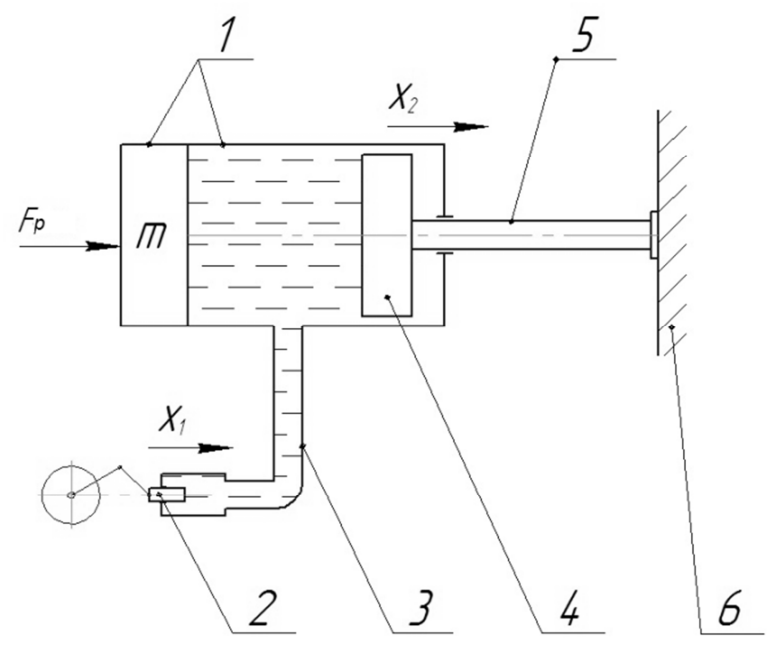

Fig. 3. Schematic diagram of the hydropulse power mechanism, where $1-$ the hydraulic cylinder case with an active weight, 2 -plunger, 3 -sleeve of high pressure, 4 -piston, 5 -boring tool, 6 -broken ground

The created impulses are formed as follows. At the movement the plunger back and forth motion executes, thus the impulses of pressure of liquid are produced, which are transferred in a hydraulic cylinder. As the hydraulic cylinder is drawn in by elastic force, there is its swing together with the inertial mass of $m$. Thus there is a periodic transformation of kinetic energy of mass $m$ to potential energy of the deformed system of liquid and a sleeve to increase of pressure in system and back. At working hours of system close to resonant, there are impulses of pressure of considerable size, which through the piston and a boring bar are transferred on the processed environment. [4]

Stable operating mode of the mechanism is above resonance, allowing to use as much as possible available system capabilities. Setting value of active mass $m$ and frequency of the compelled fluctuations of a hydropulsator plunger is possible to calculate average rigidity of the system, and then to pick up respectively rigidity air springs and hydrosprings. According to the 
experiments, due to the change of frequency of the compelled fluctuations it is possible to achieve a significant improvement of the parameters of power impulses in relation to destruction of rocks $[5,6]$.

\section{Conclusion}

One of important problems in power pulse systems is the increase of process efficiency of energy transmission on the processed environment. It is considered that a certain coordination of the parameters of the deformations waves and the characteristic of resistance of the environment to introduction of the tool in it. It can be reached by a choice of rational amplitude and frequency of impulses of power mechanisms and parameters of the destroying tool interacting with the processed environment. The power pulse machines considered above form an impulse by impact of the peel and the anvil. They are presented in schemes as impacts and vibratory impact machines. Thus impulses with sharp rise-up portion and descending part, and small on time peak value are created.

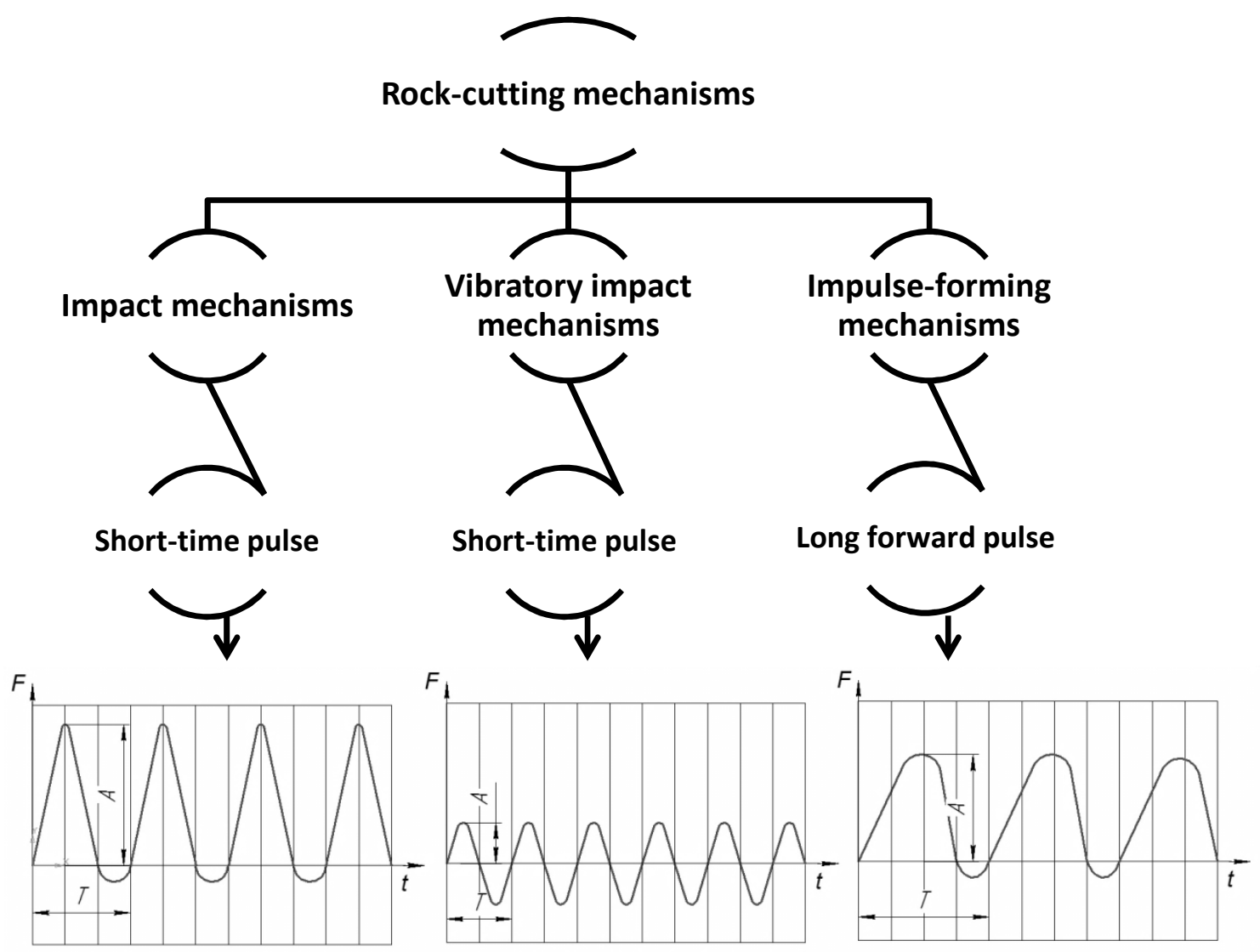

Fig. 4 Classification of power pulse mechanisms and character of impulses created by them

The offered classification of rock cutting mechanisms in Fig. 4. shows the new direction, that is pulse mechanisms. All three types of the impulses created by mechanisms on which the value of the period and amplitude is visible are presented (the values are generalized and have no concrete binding to certain mechanisms and the modes of their operation). [7]

It is known that for fuller use of energy of a power impulse, it has to have rather flat rise-up portion and sharply falling descending part. In this regard the peenless hydropulse mechanism forms impulses in a form closer to ideal, than ordinary impact mechanisms of boring machines $[8,9,10]$.

Advantages of this mechanism:

- Lack of the colliding parts

- Long-term impact on rock 
- Small noisiness during the mechanism operation

- Intrinsic safety

- Small thermal emission

- Efficiency of $75-80 \%$

The new directions of rock cutting mechanisms offer exciting possibilities for the machines using power impulses in operation.

\section{References}

[1] V. F. Gorbunov, D. N. Eshutkin, G.G. Piven, G. S. Teng. Hydraulic pick hammers and boring hammers, Novosibirsk: from Academy of Sciences of the USSR, 1982. $92 \mathrm{p}$.

[2] B. V. Sudnishnikov, N. N. Yesin, Dynamic elements of impact machines. Novosibirsk, from Academy of Sciences of the USSR, 1965. $84 \mathrm{p}$.

[3] A.M. Ashavsky, A.Ya Volpert., V.S Sheynbaum. Power pulse systems, M.: Mechanical engineering. $1978.200 \mathrm{p}$.

[4] Pashkov E. N. , Ziyakaev G. R., Tsygankova M. V. Differential equations of processes for the hydropuls power mechanism of drill machines, Applied Mechanics and Materials. 379 (2013) 91-94

[5] M. V Tsygankova. Sistem of formation of power impulses on drilling rigs for destruction of rocks of different hardness, Mountain information and analytical bulletin (the scientific and technical magazine). S4 (2013) 497-500 (477405-2014)

[6] E. N. Pashkov, G. R. Ziyakayev , P. G. Yurovsky. Increase of efficiency of shots drilling by use of headless hydropulse system, Mountain information and analytical bulletin (scientific and technical magazine). S4, 1 (2013) 521-527

[7] Pashkov E. N., Ziyakayev G. R., Kuznetsov I. V. Differential equations of processes of the hydropulse power mechanism of boring machines, Volga scientific bulletin. 4, 20 (2013) 32-36 [4428-2013]

[8] E.N. Sher, N.I. Aleksandrova, A.S. Serdechny. Transmission of impact impulse to an instrument through a liquid layer in impact machines. Journal of Mining Science. 34, 6 (1998) 498-502.

[9] A.A. Lipin, S.A. Zima, Development of gas-liquid impact machines Journal of Mining Science. 32, 6 (1996) 483-492.

[10] Vorontsov D.S., Petreev A.M. Improvement of air-distributing system of the pneumatic impact machines for trenchless technologies, Journal of Mining Science. 38, 5 (2002) 481-487. 